\title{
Corticosterone shifts reproductive behaviour towards self-maintenance in the barn owl and is linked to melanin-based coloration in females
}

\author{
Bettina Almasi ${ }^{a}, *$, Alexandre Roulin ${ }^{b}$, Lukas Jenni ${ }^{a}$ \\ a Swiss Ornithological Institute, Sempach, Switzerland \\ b Department of Ecology and Evolution, University of Lausanne, Switzerland
}

\section{A R T I C L E I N F O}

\section{Article history:}

Received 29 August 2012

Revised 6 February 2013

Accepted 8 March 2013

Available online 11 April 2013

\section{Keywords:}

Corticosterone

Reproduction

Stress-hormones

Melanism

\begin{abstract}
A B S T R A C T
Trade-offs between the benefits of current reproduction and the costs to future reproduction and survival are widely recognized. However, such trade-offs might only be detected when resources become limited to the point where investment in one activity jeopardizes investment in others. The resolution of the trade-off between reproduction and self-maintenance is mediated by hormones such as glucocorticoids which direct behaviour and physiology towards self-maintenance under stressful situations. We investigated this trade-off in male and female barn owls in relation to the degree of heritable melanin-based coloration, a trait that reflects the ability to cope with various sources of stress in nestlings. We increased circulating corticosterone in breeding adults by implanting a corticosterone-releasing-pellet, using birds implanted with a placebo-pellet as controls. In males, elevated corticosterone reduced the activity (i.e. reduced home-range size and distance covered within the home-range) independently of coloration, while we could not detect any effect on hunting efficiency. The effect of experimentally elevated corticosterone on female behaviour was correlated with their melanin-based coloration. Corticosterone (cort-) induced an increase in brooding behaviour in small-spotted females, while this hormone had no detectable effect in large-spotted females. Cort-females with small eumelanic spots showed the normal body-mass loss during the early nestling period, while large spotted cort-females did not lose body mass. This indicates that corticosterone induced a shift towards self-maintenance in males independently on their plumage, whereas in females this shift was observed only in large-spotted females.
\end{abstract}

(c) 2013 Elsevier Inc. All rights reserved.

\section{Introduction}

Lifetime reproductive success depends on a number of key decisions such as how much resource individuals invest in current vs. future reproduction and whether they produce many low-quality or few high-quality offspring (Stearns, 1992). In species with parental care, offspring fitness depends not only on genetic quality and environmental conditions but also on parental care behaviour. Birds are particularly suitable to study the trade-off between parental care behaviour and self-maintenance because incubating and feeding altricial offspring are not only energetically costly but also greatly limit the time that parents can rest and forage for themselves.

Endocrine mechanisms allow animals to resolve the trade-offs between reproduction and self-maintenance as well as between several competing reproductive activities. A class of hormones involved in

\footnotetext{
* Corresponding author at: Swiss Ornithological Institute, 6204 Sempach, Switzerland. Tel.: +4141462 9768; fax: +41414629710.

E-mail addresses: bettina.almasi@vogelwarte.ch (B. Almasi), Alexandre.Roulin@unil.ch (A. Roulin), lukas.jenni@vogelwarte.ch (L. Jenni).
}

controlling life-history trade-offs are glucocorticoids (corticosterone in birds and rodents; cortisol in fish and most mammals). Glucocorticoids are released as a response to a stress-situation to help mobilise energy reserves and to trigger behavioural changes necessary to ensure own survival, thereby reducing the investment into current reproduction.

Reproductive success depends among other things on an individual's ability to cope with unpredictable changes in environmental conditions, among them on the glucocorticoid stress response. Therefore, assessing the ability of potential mates to cope with stressful situations may be the target of sexual selection. Under stressful conditions, individuals that advertise resistance to stress to potential mates using honest signals may be preferred and have a higher reproductive success (Jacquin et al., 2012; Piault et al., 2009; Pryke et al., 2012), while under optimal environmental conditions no preference or the opposite preference may prevail. Melanin-based coloration can be such a signal, since it plays a role in mate choice (e.g. Chaine et al., 2011; Kingma et al., 2008; Senar et al., 2000) and at the same time it is related to stress sensitivity. Darker eumelanic wild vertebrates are generally more aggressive, sexually active, and resistant to stress than lighter individuals (reviewed in Ducrest et al., 2008). In several species, 
individuals with more eumelanin-based coloration have a lower release of corticosterone after an acute stress-situation than less eumelanic individuals (Almasi et al., 2010; Kittilsen et al., 2009; Schwabl, 1995) and one study showed that the expression of melanin can be hampered by elevated corticosterone levels (Roulin et al., 2008). Also the negative effects of elevated corticosterone concentration are less pronounced in more eumelanic individuals (i.e. when corticosterone is elevated barn owl nestlings with more eumelanic-spots reduced growth less than less pigmented conspecifics, Almasi et al., 2012b). Further, darker eumelanic individuals are better able to cope with a stressful situation (i.e. better withstand food depletion (Dreiss et al., 2010), breeding barn owl males with larger eumelanic spots reduce their provisioning rate less when corticosterone is elevated compared to males with less eumelanic spots (Almasi et al., 2008), salmons with more eumelanic skin pigments are less infected by parasites and show a lower corticosterone secretion to an acute stress situation (Kittilsen et al., 2012)). A possible explanation for the association between melanin and stress sensitivity is the pleiotropic effects of genes encoding for enzymes that both regulate melanin synthesis and the stress-response axis (reviewed in Ducrest et al., 2008).

The present study aims at investigating whether there is an impact of corticosterone on reproductive behaviour and whether this impact varies between parents showing different melanin-based coloration. We chose the barn owl (Tyto alba) as study species because individuals from the same population vary in the degree of eumelaninbased coloration, from a complete absence of black spots to being heavily marked with spots. We repeatedly showed that individuals with larger eumelanic spots are better able to cope with various sources of stress, have a lower corticosterone secretion to an acute stressor and are better able to regulate corticosterone levels than individuals with smaller eumelanic spots (Almasi et al., 2010, 2012b; Dreiss et al., 2010; Roulin et al., 2011a). In a recent study, we also reported that males displaying larger eumelanic spots better cope with an experimental elevation of corticosterone, i.e. the reduction in feeding rate to their brood was less affected by corticosterone in males displaying larger than small spots (Almasi et al., 2008). This suggests that corticosterone alters parental behaviour and that the extent of this effect is less pronounced in individuals displaying larger black spots. Pheomelanin-based coloration in the barn owl on the other hand is associated with investment into reproduction (Roulin and Dijkstra, 2003; Roulin et al., 2001) and not with the ability to cope with a stress-situation and therefore in the present study we focus on the hypothesis that mainly lightly pigmented individuals redirect resources from reproduction to self-maintenance when corticosterone is increased. To tackle this hypothesis, we administrated exogenous corticosterone in breeding males and females to obtain a transient increase of corticosterone in plasma. The direct manipulation of glucocorticoids avoids any potential behavioural side effects associated with applying a stressor such as manipulating food supply or brood size. Our aim was to increase plasma corticosterone for a short period of time below the level induced by an acute stressor, i.e. in the naturally observed physiological range.

Since males bring most of the food to the offspring, we manipulated breeding males during the period when offspring need for food is the highest. Females, in contrast, are responsible for brooding and feeding their offspring until they are between 2 to 3 weeks of age. We therefore manipulated corticosterone levels in females in another year than the one when we manipulated males. We formulated two main predictions: (a) Corticosterone induces breeders to divert some resources initially intended for reproduction into self-maintenance. (b) Based on the hypothesis that more eumelanic individuals better cope with stressful factors (Ducrest et al., 2008), we predicted parents with larger black spots to change their behaviour less with an experimental increase in circulating corticosterone than parents with smaller black spots.

\section{Methods}

\section{Study species}

The study was carried out in 2005 and 2006 using free-living barn owls breeding in nest-boxes $(100 \times 60 \times 50 \mathrm{~cm})$ located in western Switzerland $\left(46^{\circ} 49^{\prime} \mathrm{N} / 06^{\circ} 56^{\prime} \mathrm{E}\right)$. The two to eleven eggs are laid between February and August, and eggs hatch asynchronously on average every second or third day creating a pronounced within-brood age hierarchy. Only females incubate the eggs and thus we can distinguish them from males by the presence of a brood patch. Nestlings cannot thermo-regulate during the first two weeks and are brooded by their mother. During this time the female feeds the nestlings with pieces of meat torn from the preys the male has brought. When nestlings are thermo-independent, adults usually sleep outside the nest-box in nearby barns (own observation). All experiments were done with the permission of the Swiss committee for animal research (animal experiment permit from the "service vétérinaire du canton de Vaud" no. 1736).

\section{Manipulation of corticosterone levels in breeding males}

The experiment on males was done in 2005 and part of the experimental data have already been published in Almasi et al. (2008). In this previous paper we examined the impact of administering extra-corticosterone in male barn owls on parental feeding rates and nestling condition, but we did not investigate male home range and hunting efficiency; this is the goal of the present study.

We captured 41 male barn owls in their nest-box at night when they came feeding their $24 \pm 3$ days old offspring (mean $\pm \mathrm{SE}$ ). Upon capture we took a blood sample within 3 min to measure baseline corticosterone concentration and then we implanted 21 males with a corticosterone-releasing pellet (hereafter cort-male) and the 20 others with a placebo pellet (placebo-male). The pellets (diameter $5 \mathrm{~mm}$ ) were made up of a biodegradable carrier-binder containing $15 \mathrm{mg}$ corticosterone or, for placebo, only of the biodegradable carrier-binder (Innovative Research of America, Sarasota, Florida). We implanted the pellet under the skin of the flank above the knee through a small incision, which was closed with tissue adhesive (Histoacryl, Braun, Germany). In these males we could not determine the resulting increase in plasma corticosterone levels, because repeated captures would have caused serious disturbance and possibly caused the risk of brood abandonment. However, the increase of circulating corticosterone due to the corticosterone pellets has previously been investigated (Müller et al., 2009) and has been carefully monitored in adult females (see below) and in captive breeding females (Almasi et al., 2012a). The pellets increase baseline corticosterone for two days by a factor of four of undisturbed baseline levels while an acute handling-induced stress response increases corticosterone by a factor of six (Müller et al., 2009). From day three post-implantation onwards baseline corticosterone levels are not statistically different from pre-implantation levels, but the acute corticosterone response to handling is reduced at least until day 8 after implantation (Müller et al., 2009).

Males were weighed and their maximum wing-length was measured. AR scored breast pheomelanin-based coloration by comparison with eight colour chips from 1 for dark reddish-brown to 8 for white (for details of assessment and repeatability see Roulin, 1999). He also counted black spots located near the tip of feathers within a $60 \times 40 \mathrm{~mm}$ area on the breast and measured their diameter to the nearest $0.1 \mathrm{~mm}$. A mean spot diameter value was calculated and used for analysis (for assessment of the method and repeatability see Roulin, 2004). The age of twenty breeding males was known precisely as we banded them as nestlings $(n=20)$. Males of unknown age were classified as 'yearling' if all primary and secondary feathers belonged to the same generation, and as 'adult' otherwise (Taylor, 1993).

Mean number of nestlings on the day before males were captured was $5.7 \pm 1.2$ (SD) for cort-males and $6.3 \pm 1.4$ nestlings for 
placebo-males and did not differ between the two treatments ( $\beta$ coefficient 0.03 was not significantly different from zero as assessed by the $95 \% \mathrm{CrI}(-0.23$ to 0.28$)$ ). Clutch size, laying date and male plumage traits did not differ between the two treatment groups (all $\beta$-coefficients were not significantly different from zero as assessed by the $95 \% \mathrm{CrI}$ (all lower and upper limits beyond -0.2 and 0.3 )). Clutch size, laying date, mean nestling body mass, and number of nestlings did not covary with male plumage traits, or their mate's plumage traits, respectively (all $\beta$-coefficients were not significantly different from zero as assessed by the 95\% CrI (all lower and upper limits beyond -0.02 and 0.03 )). Male and female age did not differ between the two treatment groups (Pearson's chi-squared test: P-values $>0.58$ ).

Male provisioning rate was recorded with infrared cameras installed outside or inside the nest-boxes during the four nights following male capture. Provisioning frequency of males and females, banded on a different leg to recognize them on the video footage, was defined as the number of prey items brought to the nest-box from 22:00 until sunrise. Since prey species differ markedly in body mass, we estimated total prey mass delivered per night and then calculated the total prey biomass per night for each male (provisioning frequency). For details on the method see Almasi et al. (2008). Due to technical failures and nestlings sitting in front of the cameras we obtained provisioning rates from 117 nights (out of 176 nights) in 33 experimental nests (out of 41 nests).

\section{Male home-range and movement estimation}

Each male also received a radio-tag attached with a leg-loop harness (rubber band) on the back (Naef-Daenzer, 2007) on the day of capture. The radio-tags weighed $8 \mathrm{~g}$ ( $<3 \%$ of body mass) and the batteries lasted for at least nine month. The radio-tags fell off after roughly a year. One radio-tag stopped to function after one night and hence sample size for home-range estimation was 21 cort-males and 19 placebo-males. Following the night of capture we tracked each male for four consecutive nights using a three-element Yagi antenna and hand-held VHF receiver (R-1000, Communications Specialists Inc., CA, USA). Observation time per night was at least $1.5 \mathrm{~h}$ (mean observation time for cort-males $2.04 \pm 0.7 \mathrm{~h}$ and for placebo-males $2.0 \pm 0.5 \mathrm{~h} ; \mathrm{P}(\beta>0)=0.4$, 95\%-CrI: $-0.3-$ 0.2 ). During the observation period a single observer continuously followed the owl and estimated its position using a homing in technique as described in Kenward (2001). In total, six different persons helped following the males at night. With the positions of the birds we estimated 90\%-utilization distribution (UD) with the bivariate-normal kernel method (Worton, 1989) and calculated the home-range size in hectares for each individual using the package adehabitatHR (Calenge, 2006) for the statistical software R. We used the reference technique for the calculation of the smoothing factor $h$. The 90\%-UDs were converted to shape-files and imported into GIS. We then calculated the proportions of crop area, of wood area, and of hedges, single trees and orchards area (hereafter hedge area) within the 90\%UD using a zonal analysis (Bundesamt für Statistik, 2001).

We calculated the mean distance $(\mathrm{m})$ per hour a male covered for each night separately using the first and last position of the night plus 11 randomly chosen positions. We calculated feeding efficiency in two different ways: area used per feeding attempt (home range size divided by provisioning rate) and distance covered per feeding attempt (distance divided by provision rate).

\section{Male survival}

All males were located once a week until the end of October during the day at their roost site and we determined whether the male was alive or dead. From November until April the following year all remaining males were located once a month, except in January. When we could not find a signal of an individual anymore we searched intensively within $1 \mathrm{~km}^{2}$ around the last known position of the male. If we did not find the male dead we put the frequency of the radio transmitter on our search list. All missing individuals were repeatedly searched with an antenna fixed on the roof of the car when we were driving around to control the other males. Additionally, once a month we searched for the missing individuals from exposed places (hills, mountain tops, towers) within and at the edges of the study area. A male was considered dead only if we found the dead body or at least traces (feathers, legs, head) of the individual next to the transmitter.

\section{Manipulation of corticosterone levels in breeding females}

In 2006 we captured 22 females in their nest-box during the day. Eleven females received a corticosterone-releasing pellet (hereafter cort-females) and 11 other females a placebo pellet (placebo-females). On the day of implantation the mean number of nestlings was $4.6 \pm 1$ aged $7.0 \pm 3.9$ days (range 1-15 days) for cort-females, and $4.5 \pm 0.5$ nestlings aged $7.0 \pm 3.7$ days (range 1-14 days) for placebo females. Females were captured again 2 and 6 days after implantation (day 2 and day 6 of the experiment). Blood samples for measuring baseline plasma corticosterone concentrations were taken within 3 min after capturing the bird on all three capture occasions. An additional blood sample was taken 25 min after capturing and handling the bird on day 0 and day 6 , in order to measure corticosterone levels as a response to an acute stressor (hereafter stress-induced corticosterone). On day 6 only 16 of the 21 females were still in the nest-box and could be captured while the others spent the day outside of the nest-box. All females were weighed on each capture and the length of their wing and tarsus was measured on day 0 . Plumage traits (eumelanic dark spots and pheomelanin-based coloration of the body underparts) were determined as in males. Clutch size, number of hatchlings, nestling age, laying date and female plumage traits did not differ between the two treatment groups (all $\beta$-coefficients were not significantly different from zero as assessed by the $95 \% \mathrm{CrI}$ (all lower and upper limits beyond -0.3 to 0.4$)$ ) and did not covary with female plumage traits, or their mate's plumage traits (all $\beta$-coefficients were not significantly different from zero as assessed by the $95 \% \mathrm{CrI}$ (all lower and upper limits beyond -0.03 to 0.02 )). Male and female age did not differ between the two treatment groups (Pearson's chi-squared tests: P-values $>0.47$ ).

Infrared cameras were placed in the nest-box at the day of female implantation (day 0 ) and the behaviour of the females was recorded during the following two nights (night 1 , night 2 ). We divided the nights into 5 intervals of $1.5 \mathrm{~h}$ in length starting at 22:00 and ending at 5:00. In each interval we analysed every $15 \mathrm{~min}$ a sequence of $60 \mathrm{~s}$ (i.e. six analysed minutes) and counted the occurrence of the following seven female behaviour types: sleeping (female's eyes are closed and female is sitting on the brood), brooding (females sits on the brood with eyes open), preening offspring (female nibbles the feathers of a nestling), preening (female nibbles her own feathers), active (female is not in direct contact with her offspring, walks around or stands with eyes open and moves the head or body), feeding (female gives small pieces of prey to the offspring), eating (females eat the prey herself), absent (female is not in the nest box).

To investigate whether the manipulation of corticosterone levels in breeding females had a direct effect on offspring condition, we measured several variables in nestlings. All nestlings were measured on the day of female implantation, two, six and 14 days after female implantation. Note that 14 days after female implantation all nestlings had hatched while at the first three visits females were still incubating eggs together with the earliest hatched nestlings. Nestling body mass was measured to the nearest $\mathrm{g}$ at least once during their first 20 days of life. On the same day as measuring nestling body mass, we took a plasma sample within 3 min after opening the nest-box to record baseline corticosterone levels. We took another blood sample 25 min later to obtain a measure of handling 
stress-induced corticosterone levels. Finally, we sampled a small full blood sample to measure nestling resistance to oxidative stress.

We measured resistance to oxidative stress as the time needed to haemolyse $50 \%$ of the red blood cells exposed to a controlled free radical attack; higher values stand for higher resistance to oxidative stress. We used the KRL $®$ diagnostic test derived from human medicine, adapted to bird physiology (temperature and osmolarity (Alonso-Alvarez et al., 2004)). We submitted a whole blood cell solution to a thermocontrolled oxidative attack where all antioxidants present in blood interact to slow down red blood cell haemolysis. More specifically, $16 \mu \mathrm{l}$ of the fresh blood was added to $583 \mu \mathrm{L}$ KRL buffer $\left(150 \mathrm{mmol}^{-1} \mathrm{Na}^{+}\right.$, $120 \mathrm{mmol} \mathrm{l}^{-1} \mathrm{Cl}^{-}, 6 \mathrm{mmol} \mathrm{l}^{-1} \mathrm{~K}^{+}, 24 \mathrm{mmol} \mathrm{l}^{-1} \mathrm{HCO}_{3}, 2 \mathrm{mmol} \mathrm{l}{ }^{-1}$ $\mathrm{Ca}^{2+}, 340$ mosmol $\mathrm{l}^{-1}, \mathrm{pH}$ 7.4) for the oxidative stress analysis. All blood samples were analysed within $48 \mathrm{~h}$ of taking the blood sample.

\section{Corticosterone analysis}

Plasma total corticosterone concentration was determined using an enzyme-immunoassay (Munro and Lasley, 1988; Munro and Stabenfeldt, 1984) following Müller et al. (2006). $5 \mu$ plasma was added to $195 \mu \mathrm{l}$ water, and from this solution we extracted corticosterone with $4 \mathrm{ml}$ dichloromethane, and re-dissolved it in phosphate buffer. Each extracted probe was measured in triplicate with a self-made enzyme-immunoassay. The dilution of the corticosterone antibody (Chemicon; cross-reactivity: 11-dehydrocorticosterone $0.35 \%$, progesterone $0.004 \%$, $18-\mathrm{OH}-\mathrm{DOC} 0.01 \%$, cortisol $0.12 \%$, $18-\mathrm{OH}-\mathrm{B} 0.02 \%$ and aldosterone $0.06 \%$ ) was $1: 8,000$. We used HRP (horse-rabbit peroxidase, 1:400,000) linked to corticosterone as enzyme label and ABTS as substrate. The concentration of corticosterone in plasma samples was calculated by using a standard curve run in duplicate on each plate (range $500 \mathrm{pg} /$ well $-0.9 \mathrm{pg} /$ well). Recovery after extraction was 79\% (67-90 (95\%-CI)). Plasma pools from chicken with a low and a high corticosterone concentration were included as internal controls on each plate. Intra-assay variation ranges from 5 to $13 \%(n=111)$ and inter-assay variation from 18 to $19 \%(n=121)$, depending on the concentration of the internal control.

\section{Statistical analyses}

To analyse male home-range size, mean distance moved per hour and male feeding efficiency, we built four different statistical models using $\mathrm{R}$ version 2.12.0 (R Development Core Team, 2010). For mixed-effect models we used the library lme4 and to simulate the credible intervals the library arm. We first looked whether home-range size differed between cort- and placebo-males during the four nights following hormone manipulation. We performed a linear model with home-range size as dependent variable and age of the male (yearling or adult), implant (cort vs. placebo) as factor. We also included as covariates the number of nestlings, pheomelanin-based colour (hereafter referred to as "colour") of the male, spot-diameter of the male, proportion of hedge area present in the home-range, proportion of crop area, and proportion of wood area and the interactions 'age $\times$ implant', 'colour $\times$ implant', 'spot-diameter $\times$ implant', and 'nestling number $\times$ implant'.

Second, we built a similar model for feeding efficiency measured as home-range size divided by provisioning rate as dependent variable. In the third model, we looked at the distance the male covered per hour per night. We built a mixed-effect model with mean distance per hour as dependent variable and identity of male barn owl (hereafter male identity) and human observer (hereafter observer identity) as two random variables to account for the repeated measurements of the males and the potential differences in estimating the position of the males using telemetry by different observers. In addition to the above-mentioned factors and covariates we included the seasonal effect (date), the four different nights, and the interaction of 'night $\times$ implant' into the model. In the fourth model we looked at feeding efficiency measured as distance/provisioning rate by building a similar model as the third model. In all four models all numeric variables were centred. We always excluded the non-significant interactions by comparing the full model with a one term simpler model with a log likelihood ratio test (LR) and the more complicated model was kept when it was significantly better $(P \leq 0.05)$ as the simpler model, otherwise the simpler model was considered. We kept all the main effects in the final model. We checked the model for unequal variance structures (heteroscedasticity) by plotting standardized residuals against fitted values and looked at the qq-plots of the residuals (and random-effects) to check for normality of errors. We present the coefficients $\beta$ and the Bayesian 95\% credible intervals (CrI) for all interactions and main effects of the final model. The coefficients $\beta$ of the main effects were calculated from a model without interactions. We then calculated for each coefficient $\beta$ the posterior probability $(\mathrm{P})$ of being less than or greater than 0 by simulating 2000 random values of the posterior distribution of the $\beta$ coefficient with the library arm. The proportion of positive random values was used as posterior probability of the hypothesis that $\beta$ is larger than zero $\mathrm{P}(\beta>0)$. $\mathrm{P} \leq 0.025$ and $\mathrm{P} \geq 0.975$ were considered to indicate significant effects and presented in bold.

Note that if we included number of spots in addition to spot-diameter and the interactions of number of spots with implant or with the landscape characteristics, the results did not change significantly. Number of spots and interactions with number of spots were never significant. This means that number of spots does not explain any significant amount of variance which is not already explained by spot-diameter. For this reason, we do not present results on number of spots for the sake of clarity.

To analyse whether the corticosterone treatment affected the survival of the males, we performed two different analyses. In the first analysis we used the telemetry data until spring 2006 (max 330 days after implanting the males and attaching the radio-transmitter, this corresponds to the minimum lifespan of the battery of the transmitter). With these data we built a cox proportional hazard model including age of the males (yearling vs. adult) and implant (cort vs. placebo) as factors using the library survival. In the second analysis we used only capture-recapture data until winter 2010 (which includes the 4 breeding seasons following the male treatment). We built a mark-recapture model using the statistical platform winBUGS 14 . We included age and implant to allow for different survival probabilities of yearlings, adults, corticosterone-implanted and placebo males.

To analyse the effect of corticosterone on female behaviour we performed seven different generalized mixed-effect models with a binomial distribution for each specific behaviour type (except for the variable eating). For the variable eating, a behaviour which rarely occurred, we used occurrence (1) or absence (0) per interval and performed a similar logistic mixed regression with binomial distribution. We always included the two different nights nested in female identity as random factor to account for the repeated measurements per night and between nights. All analyses were done with the statistical package lme4 for R version 2.12.0 (R Development Core Team, 2010). We always included date, number of nestlings, pheomelanin-based coloration, mean spot-diameter and interval of the night (1-5) as covariates and age of the female (yearling or adult), implant (cort vs. placebo), and night (night 1 vs. night 2 ). All numeric variables were centred. We also included the following interactions 'implant $x$ interval', 'implant $\times$ night', 'implant $\times$ age', 'implant $\times$ number of nestlings', 'implant $\times$ colour', and 'implant $\times$ spot-diameter'. We used a similar procedure as described above to select the final model.

\section{Results}

\section{Effectiveness of the corticosterone implants in breeding females}

Before implantation females with small spot-diameter had significant stronger stress-induced corticosterone levels than females with large spot-diameter (log(stress-induced corticosterone) in relation to 
spot-diameter: coef $\beta=-0.04 \quad(-0.07 \quad-\quad-0.01 \quad 95 \%-C r I)$, $\mathrm{P}(\beta>0)=0.006$, all lower and upper limits of the $95 \% \mathrm{Crl}$ of mass, hour of the day, age and colour beyond -0.01 and 0.29 , Fig. 1 ) while baseline corticosterone was not significantly related to spot-diameter ( $\log$ (baseline corticosterone) in relation to spot-diameter: coef $\beta=-0.01$ ( -0.06 to 0.03$), P(\beta>0)=0.290$, all lower and upper limits of the $95 \% \mathrm{CrI}$ of mass, hour of the day, age and colour beyond -0.01 and 0.01 , Fig. 1). In females, corticosterone-implants increased baseline plasma corticosterone significantly from $10.7 \pm 2 \mathrm{ng} / \mathrm{ml}$ before implantation to $70.5 \pm 11.9 \mathrm{ng} / \mathrm{ml}$ two days after implantation, while placebo-females showed no significant increase in corticosterone $(12.8 \pm 2.4 \mathrm{ng} / \mathrm{ml}$, coef $\beta$ of 'day $2 \times$ implant placebo': $-1.51(-2.32--0.75), P(\beta>0)<0.001$; Fig. 2$)$. Six days after implantation, plasma corticosterone of cort-females was low again $(22.5 \pm 4.7 \mathrm{ng} / \mathrm{ml})$ and not different from levels of placebo-females $(16.4 \pm 5.4 \mathrm{ng} / \mathrm{ml}$, coef $\beta$ of 'day $6 \times$ implant placebo': $-0.48(-1.31$ to 0.36$), P(\beta>0)=0.127)$. Stress-induced levels of cort-females were significantly reduced on day six $(39.8 \pm 16.6 \mathrm{ng} / \mathrm{ml})$ compared to levels of placebo-females $(84.4 \pm 11.3 \mathrm{ng} / \mathrm{ml}$; coef $\beta$ of 'day $6 \times$ implant placebo': $1.25(0.58-1.93), \mathrm{P}(\beta>0)>0.999$; Fig. 2$)$, and were statistically not different from baseline levels (coef $\beta$ : 0.46 $(-0.47-1.47), P(\beta>0)=0.849)$, while placebo females showed a significant increase of corticosterone as a response to handling compared to baseline levels (coef $\beta$ : 1.75 (1.18-2.30), $\mathrm{P}(\beta>0)>0.999$, Fig. 2). Female spot-diameter did not explain any significant part of the variation in the increase of corticosterone due to the pellets (coef $\beta$ of 'day 2 ximplant placebo $\times$ spot-diameter': $-0.11 \quad(-0.22-0.02)$, $\mathrm{P}(\beta>0)=0.037)$. However, due to our small sample size $(\mathrm{n}=11$ females with a corticosterone implant) we had not much statistical power to detect any possible relation between the increase in corticosterone due to the implants and female spot-diameters.

\section{Effects of corticosterone on male foraging behaviour and survival}

The data very strongly support the hypothesis that elevated corticosterone levels decrease home range-size in breeding male barn owls (Table 1). Mean kernel 90\%-isopleth home range of cort-males was 544 ha \pm 54 (range $168-1157, \mathrm{n}=21$ ) and of placebo-males 806 ha \pm 91 (range $353-1873, \mathrm{n}=19$ ). There was no indication of a noticeable difference of home range size in relation to male age and plumage traits and to the number of nestlings (Table 1 ). We did not detect any relation between home-range size and landscape characteristics (proportion of crop, wood, and hedge area). None of the interactions remained in the final model.

The mean distance covered per hour did also vary significantly between the two treatment groups (Table 1). It was $4.4 \mathrm{~km} \pm 0.3$ (range 0.2-19.2) for cort-males, and $5.2 \mathrm{~km} \pm 0.4$ (range 0.5-21.9) for placebo-males. There was no indication that the distance covered per hour varied noticeably in relation to any of the male plumage traits (pheomelanin-based colour, spot-diameter), age, the number of nestlings, or the landscape characteristics. Also, there was no variation in distance covered between the four nights or along the season (Table 1).

In contrast, feeding-efficiency, measured as home range per mean provisioning rate and as distance per mean provisioning rate, did not vary with male treatment as main effect (Table 1). However, part of the individual variation in feeding efficiency could be predicted by male spot-diameter regardless of male treatment. Males with a smaller spot-diameter were more efficient hunters (i.e. small-spotted males had a smaller ratio between home range size and feeding event and a shorter distance per feeding event, Fig. 3).

The slopes of the relationship between distance covered per hour and number of nestlings varied between cort- and placebo-males (interaction implant $\times$ number of nestlings, Table 1 ). However, post-hoc tests showed that the slope of distance in relation to number of fledglings did not differ from zero in both cort- and placebo-males (cort-males: coef $\beta=0.101 \quad(-0.103-0.304), P(\beta>0)=0.832$, placebo-males: coef $\beta=-0.102(-0.207-0.06), P(\beta>0)=0032)$. When we look at feeding-efficiency, measured as distance moved per feeding attempt in relation to number of nestlings, we observed a significant difference in the slopes between cort- and placebo-males (interaction implant $\times$ number of nestlings, Table 1 ). Post-hoc tests showed that in placebo-males the slope between feeding efficiency and number of nestlings was significantly different from zero (coef $\beta=-0.264$ ( -0.420 to -0.104$), P(\beta>0)=0.000$, Fig. 4$)$, while in cort-males the slope was not significantly different from zero (coef $\beta=0.008$ ( $-0.290-0.297), P(\beta>0)=0.518$, Fig. 4). This means that placebo-males with many nestlings were less efficient compared

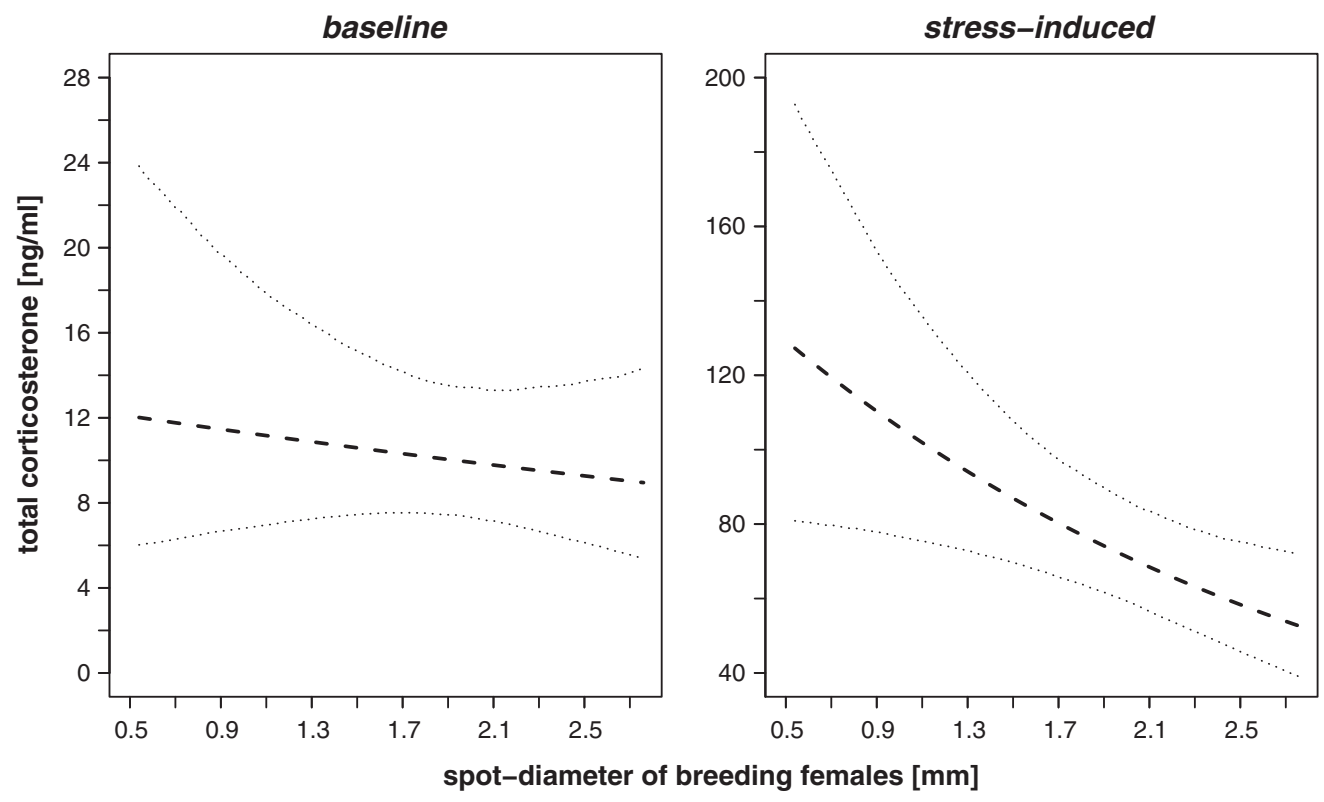

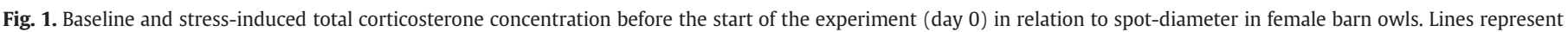
predicted corticosterone levels $\pm 95 \%$ credible intervals from the final models given in the results section. 


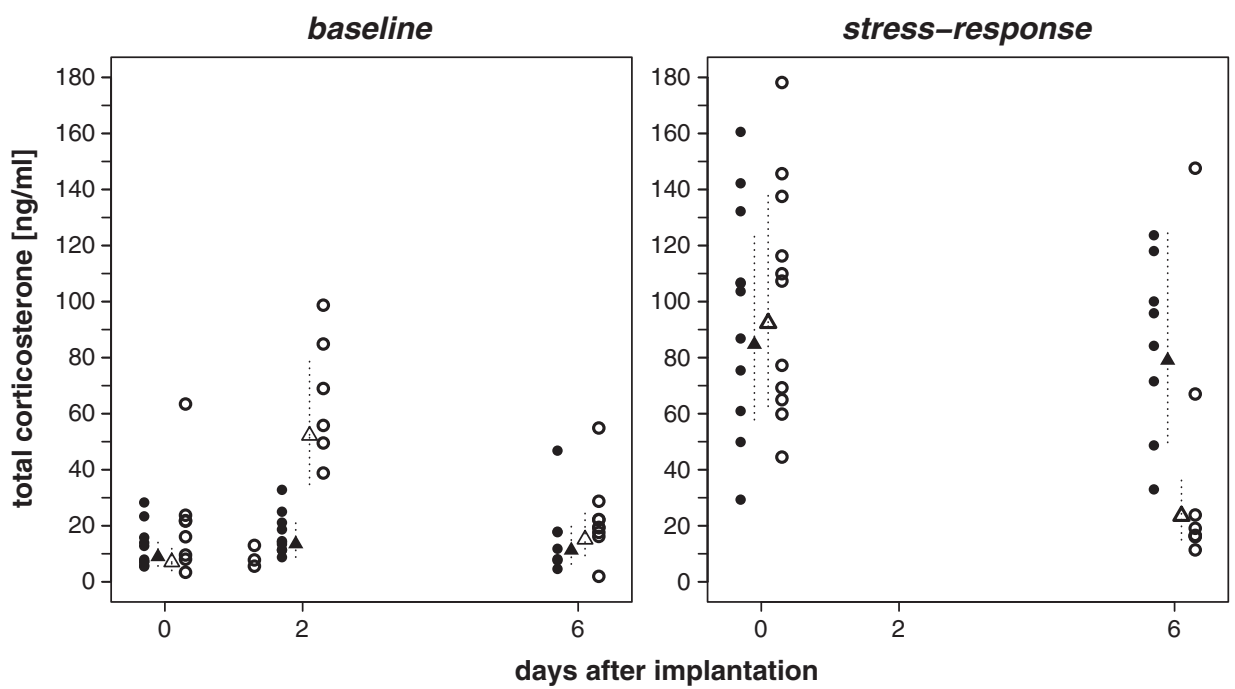

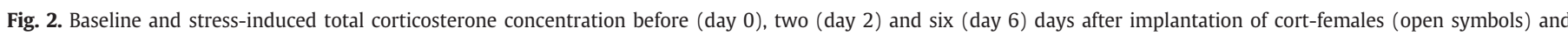
placebo-females (closed symbols) in the barn owl. Plotted are predicted means (triangles) $\pm 95 \%$ credible interval and the raw data (circles).

to placebo-males with few nestlings, while feeding efficiency in cort-males did not vary with number of nestlings.

In total we found 7 dead out of 21 cort-males and 3 dead out of 20 placebo-males. The proportional hazard model with the telemetry data until the following spring showed that cort-males tended to have a non-significantly lower survival (coef $\beta$ of cort-males $-0.835 \pm 0.69(\mathrm{SE})$ ). The mark-recapture model with capturerecapture data until the 4 th breeding season after the experimental treatment of the males showed the same non-significant trend as the proportional hazard model (coef $\beta$ of cort males $-0.16 \pm 0.44$ ).

Effects of corticosterone on female brooding behaviour, body mass and survival

We could not detect any overall effect of corticosterone treatment on any of the female behaviours (probability of sleeping, brooding, being active, being absent from the nest, feeding, preening offspring, preening, or eating, Tables 2 and 3 ) or on female mass (Table A.1). Females showed a peak in activity early in the night (higher probability of being active, being absent, and feeding offspring) while eating occurred later at night (Fig. A.1) although males bring most food items early in the night (Roulin, 2001).

The eight different types of behaviour can be grouped into behaviours associated with parental-care (brooding, feeding and preening offspring) and behaviours associated with self-maintenance (sleeping, being active, being absent, preening, and eating). Females always slept sitting on the brood, hence sleeping could not be separated from brooding. However because the female can recover from more energy demanding behaviours during sleeping, we assigned 'sleeping' to self-maintenance, rather than to parental care. When we look at behaviour probabilities associated with self-maintenance we see that the effect of corticosterone on the probability of sleeping and of being active varied with spot-diameter (Fig. 5). The probability of sleeping was enhanced in small-spotted cort-females compared to small-spotted placebo-females, while the

Table 1

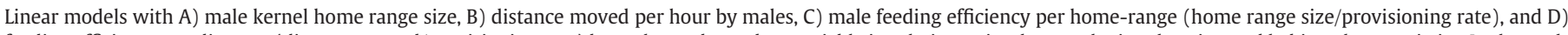

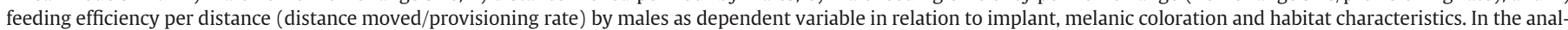

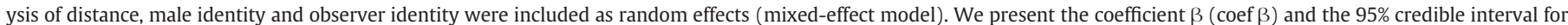

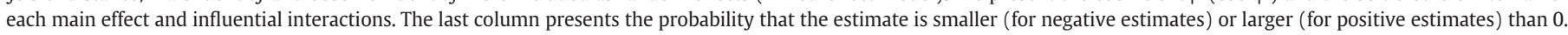

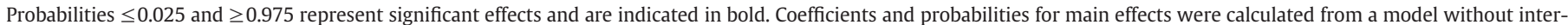
actions. Analyses are based on 40 male home ranges and on 160 distance measurement of 40 males.

\begin{tabular}{|c|c|c|c|c|c|c|c|c|c|c|c|c|}
\hline & \multicolumn{3}{|c|}{ A) $\log$ (home-range size) } & \multicolumn{3}{|c|}{ B) $\log$ (distance) } & \multicolumn{3}{|c|}{$\begin{array}{l}\text { C) Log(home-range size/feeding } \\
\text { rate) }\end{array}$} & \multicolumn{3}{|c|}{ D) $\log$ (distance/feeding rate) } \\
\hline & Coef $\beta$ & $\begin{array}{l}\text { 95\% credible } \\
\text { interval }\end{array}$ & $P(\beta>0)$ & Coef $\beta$ & $\begin{array}{l}95 \% \text { credible } \\
\text { interval }\end{array}$ & $P(\beta>0)$ & Coef $\beta$ & $\begin{array}{l}\text { 95\% credible } \\
\text { interval }\end{array}$ & $\mathrm{P}(\beta>0)$ & Coef $\beta$ & $\begin{array}{l}\text { 95\% credible } \\
\text { interval }\end{array}$ & $\mathrm{P}(\beta>0)$ \\
\hline Intercept & 6.26 & 5.90 to 6.62 & & 8.11 & $7.82-8.39$ & & 1.07 & $0.55-1.62$ & & 2.86 & $2.38-3.33$ & \\
\hline Date & & & - & 0.00 & $-0.01-0.01$ & 0.621 & & & - & 0.00 & $-0.01-0.01$ & 0.716 \\
\hline Age adult & -0.13 & -0.52 to 0.29 & 0.265 & 0.12 & $-0.18-0.42$ & 0.778 & -0.39 & $-1.01-0.22$ & 0.103 & -0.13 & $-0.62-0.36$ & 0.313 \\
\hline $\mathrm{nb}$ of nestlings & 0.05 & -0.08 to 0.19 & 0.784 & -0.03 & $-0.12-0.05$ & 0.232 & -0.07 & $-0.25-0.11$ & 0.209 & -0.12 & $-0.25-0.02$ & 0.052 \\
\hline Colour & -0.01 & -0.14 to 0.11 & 0.425 & 0.00 & $-0.09-0.08$ & 0.462 & -0.01 & $-0.18-0.15$ & 0.442 & -0.01 & $-0.15-0.13$ & 0.415 \\
\hline Spot-diameter (dia) & 0.01 & -0.03 to 0.04 & 0.646 & 0.01 & $-0.01-0.03$ & 0.849 & 0.05 & 0.04-0.09 & 0.981 & 0.05 & $0.02-0.08$ & 0.999 \\
\hline Implant placebo & 0.44 & 0.10 to 0.78 & 0.991 & 0.26 & $0.04-0.48$ & 0.987 & -0.01 & $-0.47-0.41$ & 0.483 & -0.09 & $-0.40-0.23$ & 0.298 \\
\hline Night & & & - & 0.08 & $-0.04-0.20$ & 0.898 & & & - & 0.02 & $-0.20-0.23$ & 0.559 \\
\hline Proportion of hedge area & 0.01 & -0.08 to 0.10 & 0.595 & 0.02 & $-0.04-0.08$ & 0.749 & -0.05 & $-0.16-0.08$ & 0.226 & -0.02 & $-0.11-0.08$ & 0.349 \\
\hline Proportion of crop area & -0.01 & -0.03 to 0.02 & 0.388 & 0.01 & $-0.02-0.03$ & 0.658 & -0.01 & $-0.04-0.03$ & 0.371 & 0.00 & $-0.04-0.04$ & 0.536 \\
\hline Proportion of wood area & -0.01 & -0.04 to 0.01 & 0.175 & 0.00 & $-0.02-0.02$ & 0.432 & -0.02 & $-0.06-0.02$ & 0.159 & 0.00 & $-0.04-0.04$ & 0.443 \\
\hline Night $\times$ implant placebo & & & $\mathrm{rm}$ & & & $\mathrm{rm}$ & & & $\mathrm{rm}$ & & & $\mathrm{rm}$ \\
\hline Age $\times$ implant placebo & & & $\mathrm{rm}$ & & & $\mathrm{rm}$ & & & $\mathrm{rm}$ & & & $\mathrm{rm}$ \\
\hline Colour $\times$ implant placebo & & & $\mathrm{rm}$ & & & $\mathrm{rm}$ & & & $\mathrm{rm}$ & & & $\mathrm{rm}$ \\
\hline Dia $\times$ implant placebo & & & $\mathrm{rm}$ & & & $\mathrm{rm}$ & & & $\mathrm{rm}$ & & & $\mathrm{rm}$ \\
\hline $\mathrm{nb}$ of nestling $\times$ implant placebo & & & $\mathrm{rm}$ & -0.185 & $-0.037--0.002$ & 0.023 & & & $\mathrm{rm}$ & -0.35 & $-0.60--0.11$ & 0.004 \\
\hline
\end{tabular}




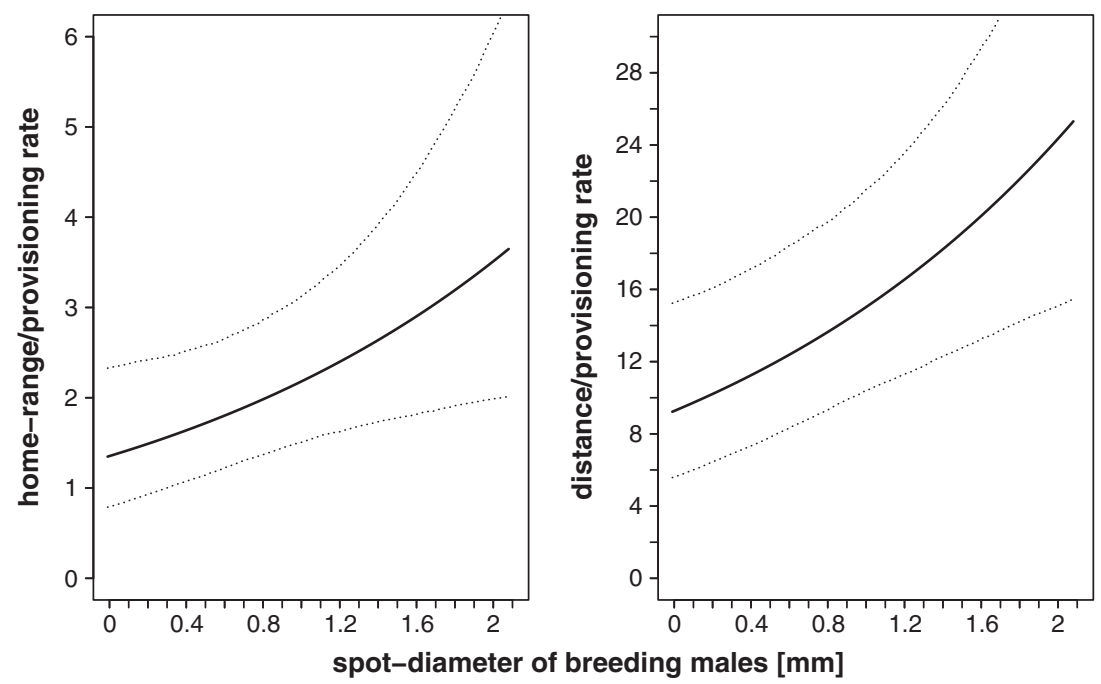

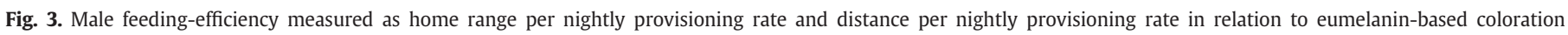

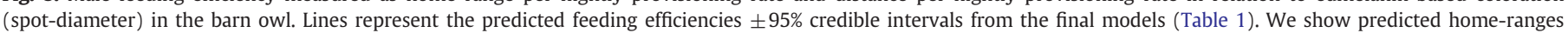
and feeding efficiencies over the whole observed spot-diameter range. All other co-variables were set to their mean value.

effect of corticosterone on sleeping probability was negligible in largespotted females. The probability of being active was reduced in smallspotted cort-females compared to small-spotted placebo-females, while there was hardly any effect of cort-treatment in large spotted females (Fig. 5). Independently of corticosterone treatment, females with large spots preened themselves less than females with smaller spot-diameter.

When we look at the individual variation in behaviour probabilities associated with parental-care, we see that the probability of preening offspring was significantly associated with pheomelanin-based coloration by being lower in whitish placebo-females compared to reddish-brown placebo-females (Fig. 5). In addition, corticosterone reduced significantly the probability of preening offspring in reddish-brown cort-females compared to reddish-brown placebo-females, while the effect of corticosterone on preening offspring was almost negligible in whitish individuals (Fig. 5). Placebo-females displaying larger eumelanic spots showed a significant higher probability of brooding compared to placebo-females displaying smaller spots (Fig. 5), while elevated corticosterone levels resulted in significantly reduced brooding probabilities in large-spotted females compared to large-spotted placebo individuals.

Individual variation in female body mass was significantly associated with eumelanin-based coloration (i.e. spot size). Six days after corticosterone implantation, cort-females with large-spots had a significant higher body mass compared to large-spotted placebo-females and small-spotted cort-females (Table A.1, Fig. 6), while at the day of corticosterone implantation and two days later body mass was not significantly related to spot-diameter (Table A.1). Males of cort- and placebo-females brought a similar amount of food to the nest and male feeding rate was not significantly associated with mother spot diameter alone or interaction with cort-treatment (Table A.1).

Out of the 22 experimental females only one was found dead until the 4 th breeding season after the experiment which prevented us to analyse these data. However a similar proportion of females ( 7 of the 11 cort-females and 6 of the 11 placebo females) bred in our study area again in the next year.

Effects of maternal corticosterone treatment on nestling growth, physiology and survival until fledging

Maternal treatment did not significantly affect nestling body mass, nestling baseline and stress-induced corticosterone levels, or nestling resistance to oxidative stress during the first 20 days post-hatching (Table A.2). The number of fledglings was not significantly associated with maternal treatment, maternal coloration, or maternal spot-diameter, nor

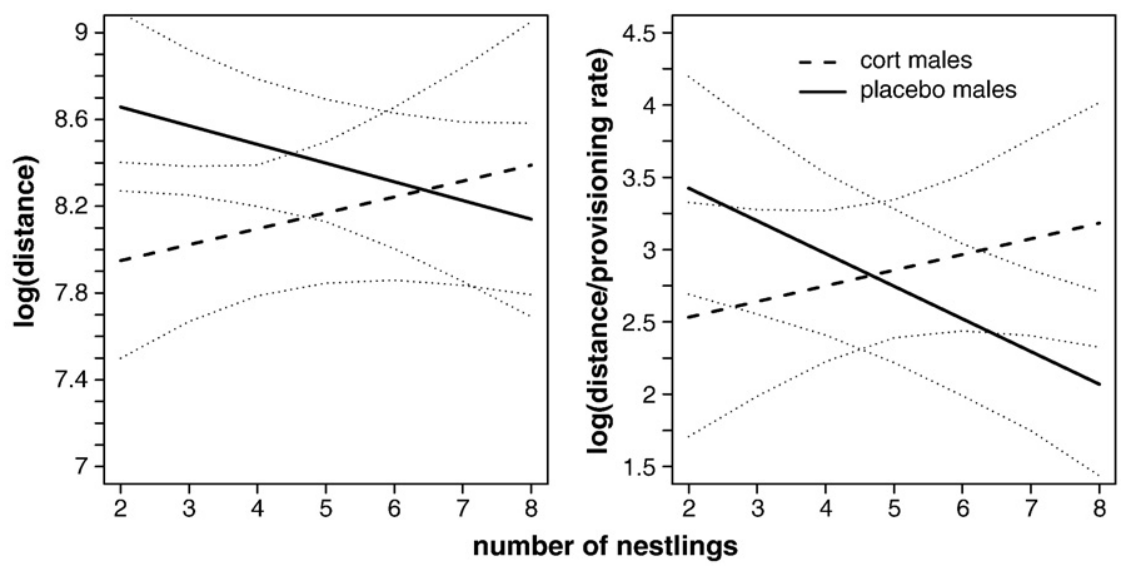

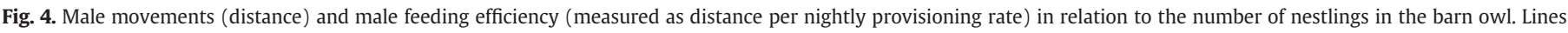

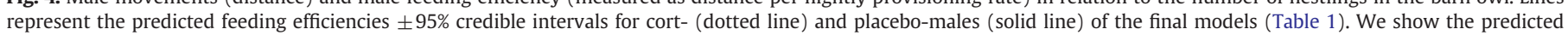
distances and feeding efficiencies over the whole observed range of brood sizes. All other co-variables were set to their mean value. 


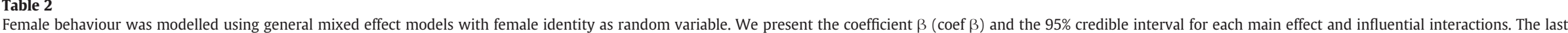

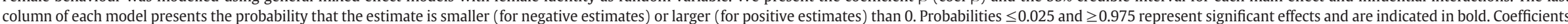
and probabilities for main effects were calculated from a model without interactions. Analyses are based on 204 observations of 21 females of 2 nights.

\begin{tabular}{|c|c|c|c|c|c|c|c|c|c|c|c|c|}
\hline & \multicolumn{3}{|c|}{ Brooding } & \multicolumn{3}{|c|}{ Sleeping } & \multicolumn{3}{|l|}{ Active } & \multicolumn{3}{|l|}{ Absent } \\
\hline & $\operatorname{Coef} \beta$ & $95 \%$ credible interval & $\mathrm{P}(\beta>0)$ & $\operatorname{Coef} \beta$ & $95 \%$ credible interval & $P(\beta>0)$ & $\operatorname{Coef} \beta$ & $95 \%$ credible interval & $P(\beta>0)$ & $\operatorname{Coef} \beta$ & $95 \%$ credible interval & $P(\beta>0)$ \\
\hline Intercept & 2.25 & 0.49 to 3.94 & & -0.84 & $-1.70-0.08$ & & -2.09 & $-2.77--1.37$ & & -1.51 & -2.54 to -0.55 & \\
\hline Date & -0.04 & -0.09 to 0.02 & 0.105 & -0.02 & $-0.05-0.01$ & 0.035 & 0.00 & $-0.02-0.03$ & 0.627 & -0.01 & $-0.01-0.05$ & 0.898 \\
\hline Age adult & -1.21 & -2.89 to 0.49 & 0.076 & 0.02 & $-0.93-0.89$ & 0.514 & 0.44 & $-0.23-1.08$ & 0.893 & 0.09 & $-0.86-1.05$ & 0.586 \\
\hline nb of nestlings & 0.326 & -0.35 to 1.05 & 0.796 & 0.04 & $-0.31-0.38$ & 0.590 & -0.09 & $-0.36-0.17$ & 0.256 & -0.16 & $-0.59-0.27$ & 0.239 \\
\hline Colour & -0.334 & -0.92 to 0.19 & 0.112 & -0.12 & $-0.42-0.16$ & 0.207 & 0.19 & $-0.03-0.41$ & 0.949 & 0.20 & $-0.11-0.52$ & 0.892 \\
\hline Spot-diameter (dia) & 0.089 & -0.04 to 0.22 & 0.921 & 0.05 & $-0.01-0.12$ & 0.946 & -0.03 & $-0.08-0.02$ & 0.139 & -0.04 & $-0.11-0.03$ & 0.125 \\
\hline Implant placebo & -0.06 & -1.49 to 1.33 & 0.479 & -0.37 & $-1.08-0.35$ & 0.161 & 0.00 & $-0.56-0.52$ & 0.498 & 0.05 & $-0.77-0.82$ & 0.546 \\
\hline Interval 2 (23:30-00:45) & 0.28 & -0.29 to 0.86 & 0.848 & -0.08 & $-0.51-0.34$ & 0.348 & -0.76 & -1.31 to -0.19 & 0.004 & -0.66 & -1.24 to -0.07 & 0.016 \\
\hline Interval $3(01: 30-02: 15)$ & 0.66 & 0.12 to 1.21 & 0.992 & 0.33 & $-0.10-0.74$ & 0.947 & -0.46 & $-0.97-0.04$ & 0.033 & -0.91 & -1.53 to -0.33 & $<0.001$ \\
\hline Interval $4(02: 30-03: 45)$ & 1.31 & 0.69 to 1.26 & 1.000 & 0.61 & $0.18-1.01$ & 0.995 & -0.84 & -1.41 to -0.25 & 0.000 & -1.20 & -1.85 to -0.55 & $<0.001$ \\
\hline Interval 5 (04:00-05:15) & 1.30 & 0.70 to 1.93 & 1.000 & 0.80 & $0.41-1.21$ & 1.000 & -0.88 & -1.46 to -0.28 & 0.001 & -1.50 & -2.17 to -0.85 & $<0.001$ \\
\hline Night & -0.74 & -1.42 to -0.10 & 0.013 & -0.43 & -0.82 to -0.07 & 0.009 & 0.28 & $-0.22-0.80$ & 0.850 & 0.14 & $-0.33-0.65$ & 0.707 \\
\hline Nigth $\times$ implant placebo & & & $\mathrm{rm}$ & & & $\mathrm{rm}$ & & & $\mathrm{rm}$ & & & $\mathrm{rm}$ \\
\hline Age $\times$ implant placebo & & & $\mathrm{rm}$ & & & $\mathrm{rm}$ & & & $\mathrm{rm}$ & & & $\mathrm{rm}$ \\
\hline Colour $\times$ implant placebo & & & $\mathrm{rm}$ & & & $\mathrm{rm}$ & & & $\mathrm{rm}$ & & & $\mathrm{rm}$ \\
\hline Dia $\times$ implant placebo & 0.27 & 0.03 to 0.51 & 0.987 & 0.13 & $0.01-0.25$ & 0.975 & -0.14 & -0.22 to -0.05 & 0.001 & & & $\mathrm{rm}$ \\
\hline Interval $\times$ implant placebo & & & $\mathrm{rm}$ & & & $\mathrm{rm}$ & & & $\mathrm{rm}$ & & & $\mathrm{rm}$ \\
\hline Nestling $\times$ implant placebo & & & $\mathrm{rm}$ & & & $\mathrm{rm}$ & & & $\mathrm{rm}$ & & & $\mathrm{rm}$ \\
\hline
\end{tabular}

Table 3

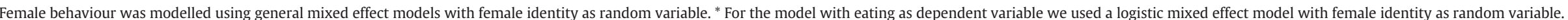

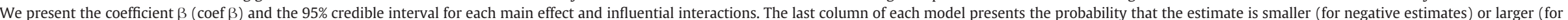

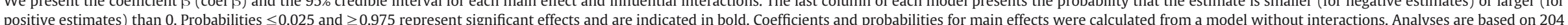
positive estimates) than 0 . Probabilities $\leq 0.025$
observations of 21 females during 2 nights.

\begin{tabular}{|c|c|c|c|c|c|c|c|c|c|c|c|c|}
\hline & \multicolumn{3}{|c|}{ Feeding offspring } & \multicolumn{3}{|c|}{ Preening offspring } & \multicolumn{3}{|c|}{ Preening } & \multicolumn{3}{|l|}{ Eating* } \\
\hline & $\operatorname{Coef} \beta$ & $95 \%$ credible interval & $\mathrm{P}(\beta>0)$ & $\operatorname{Coef} \beta$ & $95 \%$ credible interval & $\mathrm{P}(\beta>0)$ & Coef $\beta$ & $95 \%$ credible interval & $\mathrm{P}(\beta>0)$ & Coef $\beta$ & $95 \%$ credible interval & $P(\beta>0)$ \\
\hline Intercept & -1.56 & -2.08 to -1.06 & & -0.85 & $-1.95--0.73$ & & -3.26 & $-4.08--2.39$ & & -1.32 & -2.39 to -0.26 & \\
\hline Date & 0.01 & -0.00 to 0.02 & 0.959 & -0.03 & $-0.05--0.01$ & 0.001 & -0.03 & $-0.05--0.01$ & 0.009 & 0.01 & $-0.02-0.03$ & 0.653 \\
\hline Age adult & -0.67 & -1.06 to -0.26 & 0.001 & -0.24 & $-0.81-0.38$ & 0.206 & -0.51 & $-0.99--0.03$ & 0.019 & 0.01 & $-0.83-0.79$ & 0.504 \\
\hline $\mathrm{nb}$ of nestlings & -0.05 & -0.24 to 0.13 & 0.291 & -0.18 & $-0.43-0.06$ & 0.072 & -0.11 & $-0.35-0.13$ & 0.195 & -0.04 & $-0.35-0.30$ & 0.403 \\
\hline Colour & 0.03 & -0.11 to 0.16 & 0.679 & 0.13 & $-0.06-0.32$ & 0.911 & 0.01 & $-0.17-0.17$ & 0.512 & 0.22 & $-0.04-0.49$ & 0.942 \\
\hline Spot-diameter (dia) & 0.02 & -0.02 to 0.05 & 0.846 & 0.01 & $-0.04-0.05$ & 0.625 & -0.04 & $-0.08--0.01$ & 0.018 & 0.02 & $-0.04-0.08$ & 0.710 \\
\hline Implant placebo & 0.16 & -0.18 to 0.52 & 0.814 & 0.11 & $-0.36-0.56$ & 0.680 & 0.37 & $-0.09-0.84$ & 0.940 & -0.04 & $-0.69-0.60$ & 0.455 \\
\hline Interval 2 (23:30-00:45) & 0.52 & 0.03 to 1.05 & 0.980 & -0.20 & $-0.66-0.25$ & 0.203 & 0.79 & $-0.10-0.22$ & 0.961 & -0.14 & $-1.14-0.86$ & 0.394 \\
\hline Interval $3(01: 30-02: 15)$ & 0.12 & -0.45 to 0.66 & 0.651 & -0.08 & $-0.57-0.34$ & 0.358 & 1.34 & $0.44-2.11$ & 0.999 & 0.23 & $-0.69-1.31$ & 0.709 \\
\hline Interval $4(02: 30-03: 45)$ & 0.27 & -0.28 to 0.80 & 0.854 & 0.23 & $-0.19-0.66$ & 0.843 & 0.85 & $-0.02-0.26$ & 0.972 & 0.40 & $-0.58-1.411$ & 0.793 \\
\hline Interval 5 (04:00-05:15) & 0.01 & -0.56 to 0.57 & 0.511 & 0.19 & $-0.25-0.56$ & 0.815 & 1.13 & $0.26-1.96$ & 0.995 & -1.09 & $-2.25-0.17$ & 0.046 \\
\hline Night & -0.22 & -0.56 to 0.14 & 0.106 & -0.22 & $-0.51-0.07$ & 0.066 & -0.25 & $-0.73-0.21$ & 0.144 & 0.31 & $-0.38-0.97$ & 0.813 \\
\hline Night $\times$ implant placebo & & & $\mathrm{rm}$ & -0.89 & $-1.47--0.30$ & 0.002 & & & $\mathrm{rm}$ & & & $\mathrm{rm}$ \\
\hline Age $\times$ implant placebo & & & $\mathrm{rm}$ & -1.27 & $-2.29--0.21$ & 0.013 & & & $\mathrm{rm}$ & & & $\mathrm{rm}$ \\
\hline Colour $\times$ implant placebo & & & $\mathrm{rm}$ & -0.54 & $-0.85--0.22$ & $<0.001$ & & & $\mathrm{rm}$ & & & $\mathrm{rm}$ \\
\hline Dia $\times$ implant placebo & & & $\mathrm{rm}$ & & & $\mathrm{rm}$ & & & $\mathrm{rm}$ & & & $\mathrm{rm}$ \\
\hline Interval $\times$ implant placebo & & & $\mathrm{rm}$ & & & $\mathrm{rm}$ & & & $\mathrm{rm}$ & & & $\mathrm{rm}$ \\
\hline Nestling $\times$ implant placebo & & & $\mathrm{rm}$ & & & $\mathrm{rm}$ & & & $\mathrm{rm}$ & & & $\mathrm{rm}$ \\
\hline
\end{tabular}



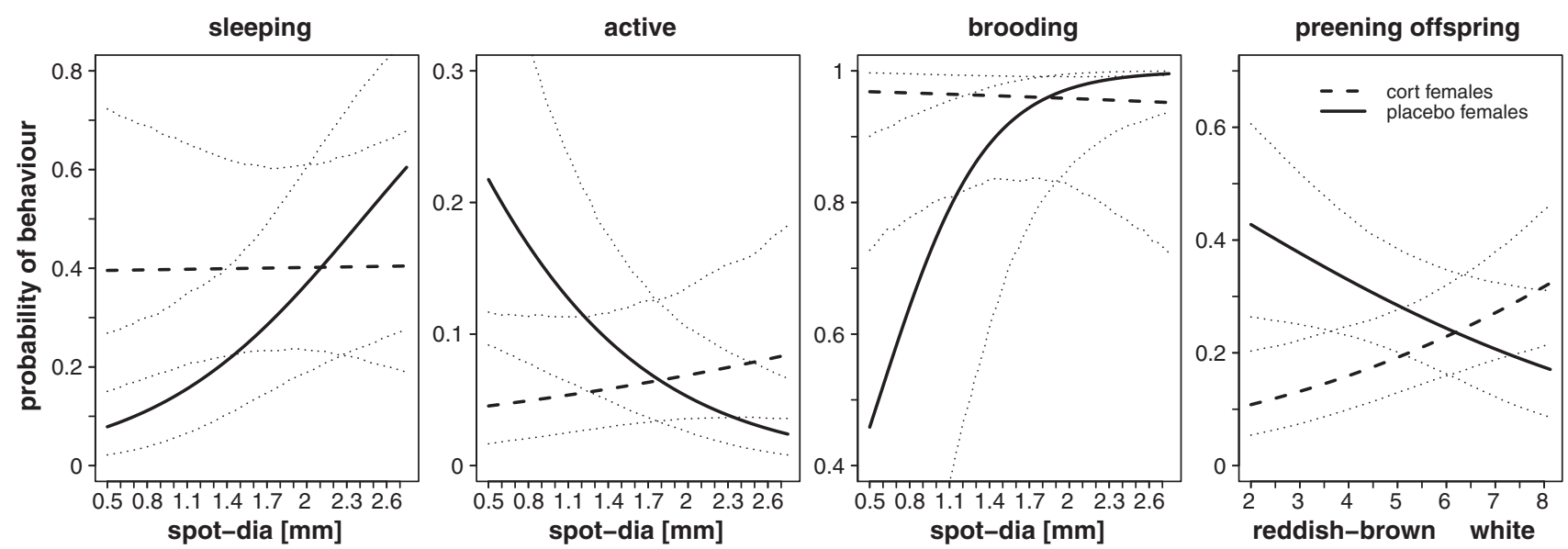

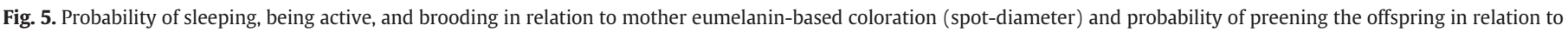

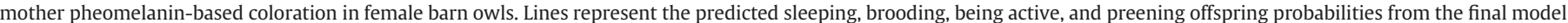

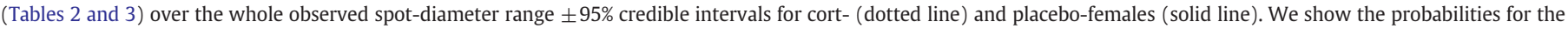
first night at the time interval 3 (01:00-02:15 a.m). All other co-variables were set to their mean value.

with the interactions "maternal implant $\times$ spot-diameter" and "maternal implant $\times$ colour" (all $\mathrm{P}(\beta>0)$ between 0.16 and 0.95 ).

\section{Discussion}

Effort invested in current reproduction is traded-off against investment in both future reproduction and self-maintenance and in turn survival. Under stressful conditions the conflict between selfmaintenance and reproductive effort is escalated and hence individual variation in the ability to resolve this trade-off may be the target of intense selection. The present study showed that a moderate increase of the stress-hormone corticosterone over two days during reproduction in both male and female barn owls affected parental care without leading to brood abandonment. In males, elevated corticosterone resulted in a reduction in home-range size and distance travelled throughout the night independently of plumage traits. In females the effects of corticosterone on behaviours associated with parental care and self-maintenance was pronounced but only in individuals displaying large rather than small black spots.
The pellets elevated plasma corticosterone for a short period of time ( 2 days) and possibly affected the negative feedback mechanism for a bit longer as suggested by the reduced acute corticosterone response to handling six days after implantation in cort-females. There was considerable variability between individuals in the increase of corticosterone induced by the pellets and in the reduction of the acute corticosterone response to handling (two of 11 females showed almost no increase in baseline corticosterone and had no reduced acute corticosterone response). The large variability may be correlated with spot diameter as we showed in nestlings (Almasi et al., 2010). In the present study the sample size of cort-females was quite low, which was most likely the reason why we did not detect a correlation between the increase in corticosterone due to the pellets and spot-diameter of the females.

\section{Effects of corticosterone on male behaviour}

Breeding male barn owls with increased corticosterone levels significantly decreased their home-range size by a factor of 1.5 and distance covered per hour by a factor of 1.2 compared to the placebo group. This resulted in a lower feeding rate by cort-males compared
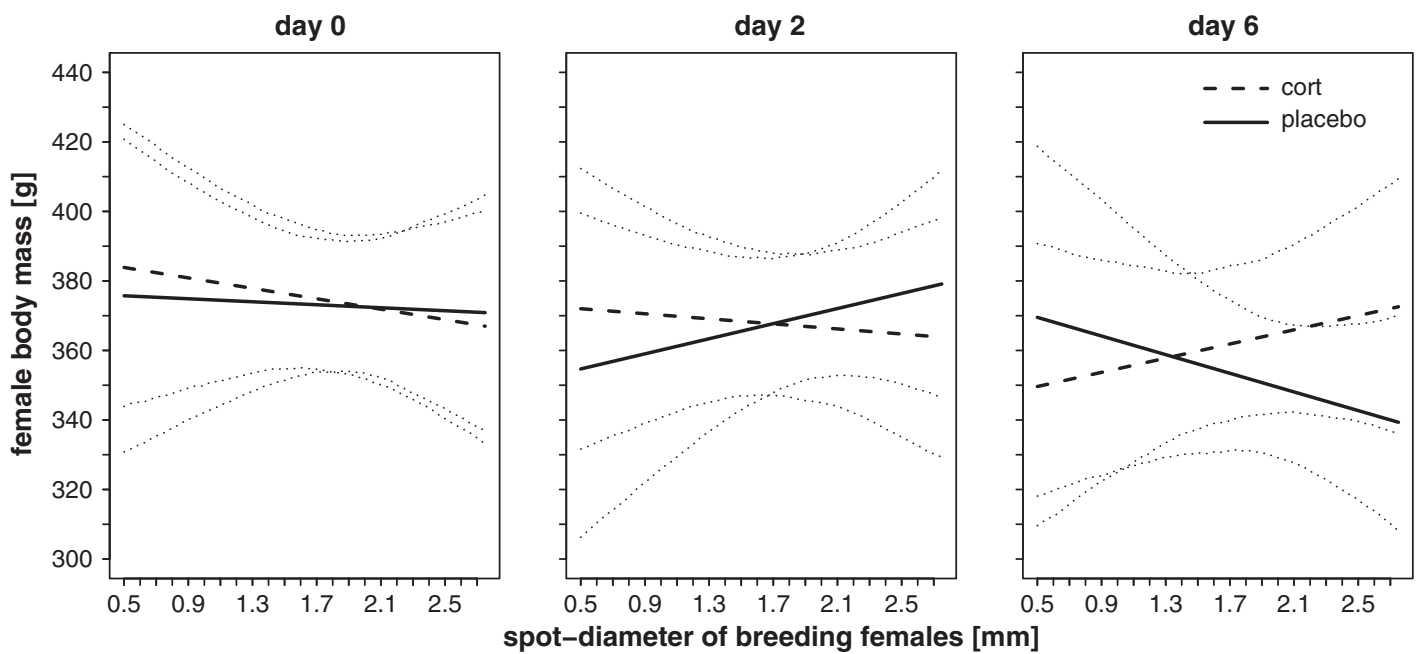

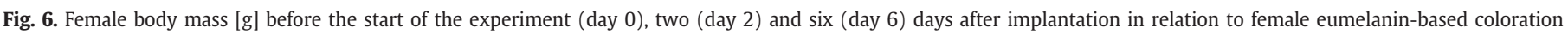

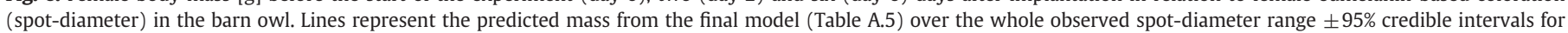
cort- (dotted line) and placebo-females (solid line). All other co-variables were set to their mean value. Cort- and placebo-females significantly differ on day 6 (Table A.5). 
to placebo-males (Almasi et al., 2008). Interestingly, the feeding efficiency measured as the patrolled area necessary to capture a prey item for the progeny and as the distance covered to capture a prey item did not vary between males with experimentally elevated corticosterone levels or the control group Thus, breeding males with experimentally elevated corticosterone levels are as efficient in foraging for their offspring as placebo-males, but they apparently rest more at the expense of feeding rate. This indicates that in a situation of elevated corticosterone males redirect resources initially devoted to reproduction into self-maintenance.

One of the few studies looking at home-range size found a context-dependent effect of corticosterone. In side-blotched lizards (Uta stansburiana) a corticosterone implant reduced home-range size only in the presence of non-implanted lizards that are more aggressive (DeNardo and Sinervo, 1994). In our study, cort-males reduced home-range size regardless of habitat characteristics and plumage traits. The decrease in home-range size goes along with a decrease in feeding rate (Almasi et al., 2008) which resulted in lower body mass gain of their nestlings (Almasi et al., 2008) during the time when corticosterone was elevated. However, the negative impact on nestling body condition ceased once circulating corticosterone returned to starting levels. Indeed, the offspring of cort- and placebo-males showed a similar fledging success and they fledged with a similar body mass (Almasi et al., 2008). We thus conclude that the negative effect of extra-corticosterone was transient and that cort-males or their female partners could later compensate for the temporary reduction of the feeding rate.

\section{Paternal care in relation to the size of black spots}

In a previous study using the same individuals, we showed that males displaying larger black spots had a lower feeding rate than those with smaller spots (Almasi et al., 2008). In the present study, we add new information, namely that independently of the experimental treatment large-spotted males were also less efficient in hunting for their brood (i.e. they flew longer distances per prey item brought to their offspring) than smaller-spotted males. This is in line with the hypothesis of sexually antagonistic selection prevailing on spot size, namely females with large spots having a selective advantage, whereas males with large spots being counter-selected (Roulin et al., 2010; see also Roulin et al., 2011b). We thus conclude that if cort-implantation induced a weaker reduction in feeding rate in large- than small-spotted males (Almasi et al., 2008), this is not because large-spotted males better coped with extra-corticosterone but because their initial investment to forage for their offspring was lower compared to small-spotted males (see Fig. 1 in Almasi et al., 2008). Indeed, independently of treatment home-range size was similar in differently-spotted males indicating that large-spotted males are less efficient at exploiting their territory than small-spotted males and as a consequence they feed their offspring at a lower rate (Almasi et al., 2008).

\section{Effects of corticosterone on female behaviour}

In females, elevated corticosterone affected several caring behaviours differentially in relation to the size of eumelanic spots. Small-spotted females shifted their behaviour more towards a passive strategy when stress-hormones were experimentally elevated (they slept and brooded more and were less active) compared to smallspotted placebo-females. On the other hand large-spotted females with elevated stress-hormone levels showed hardly any behavioural change compared to the control group. It therefore seems that small-spotted females are particularly sensitive to a rise in corticosterone levels. In accordance, independently of corticosterone treatment small-spotted females showed, as a response to an acute handling stress, a stronger rise in corticosterone than large spotted-females (present study), a relationship that we already demonstrated in nestlings (Almasi et al., 2010). Furthermore, nestlings born from mothers with large spots quicker reduced elevated corticosterone levels (Almasi et al., 2010). By clearing exogenous corticosterone more rapidly, larger-spotted individuals (i.e. nestlings and mothers) may therefore be less sensitive to a rise in corticosterone either through the implantation of a corticosterone-releasing pellet or a stressful event.

Females start to loose body mass on average nine days after hatching of the first egg which is about the time when the energy demand of the nestlings and the mother cannot be satisfied by the male alone anymore and females need to help hunting prey for their offspring (Durant et al., 2004). Therefore, during the time when we monitored female weight (from 7 to 12 days after hatching of the first egg) females usually loose body mass (Durant et al., 2004). However, this body mass loss was only observed in cort-females displaying small spots, whereas cort-females with large spots did not lose body mass. Thus, possibly large-spotted cort-females delay the time when they will start helping their mate to hunt prey items. This difference in body mass loss between large- and small-spotted cort-females indicates that a shift from brood caring to self-maintenance occurred in females displaying larger black spots and probably also explains why those females have a higher survival (Roulin and Altwegg, 2007).

Independently of corticosterone (placebo-group) females displaying larger black spots brooded and slept more and were less active, and darker reddish phaeomelanic females preened their young more often than whitish females. From recent studies it is known that in the barn owl mothers with larger black spots perform better in a number of fitness-related parameters (higher body mass in the evening (Roulin, 2009), higher calcium bone content (Roulin et al., 2006), start to breed at a younger age and higher survival (Roulin and Altwegg, 2007)) compared to smaller-spotted females. We thus conclude that in relatively relaxed conditions larger-spotted females take more time to rest than smaller-spotted conspecifics (even if they brood longer their offspring, this behaviour is rather passive), whereas darker phaeomelanic females are more active in their caring behaviour than lighter phaeomelanic conspecifics.

Despite the widely assumed hypothesis that corticosterone changes behaviour from reproduction towards self-maintenance (Sapolsky et al., 2000) we did not observe any effect of the female corticosterone treatment on their offspring including body condition, corticosterone levels, resistance to oxidative stress, and survival until fledging. During the time of the experiment females did not need to hunt and therefore may relatively easily cope with the extra corticosterone.

\section{Conclusions}

An experimental elevation of corticosterone induced a shift towards self-maintenance in breeding males independently of their plumage coloration, whereas in breeding females this shift was observed only in large-spotted individuals. Breeding male barn owls, the sex which provides most prey item to the offspring, reduced their activity and offspring feeding rate (Almasi et al., 2008) drastically. However, once the stress-situation ceased about three days after implantation, these males fully resumed their parental activities so that at the time of fledging we could no more observe any negative impact of this manipulation on their offspring. This short period of elevated corticosterone did not affect male survival significantly and males could make up for their reduced brood caring behaviour afterwards. A longer period of elevated glucocorticoids would most likely result in lower survival or/and lower reproductive success of these males. In females the effects of an experimental elevation of corticosterone covaried with the size of black spots: individuals displaying large black spots shifted their behaviour towards self-maintenance.

Supplementary data to this article can be found online at http:// dx.doi.org/10.1016/j.yhbeh.2013.03.001. 


\section{Acknowledgments}

We warmly thank Martin Amrein, Silvain Antoniazz, Silvan Bissegger, Juliette Jullierat, Pascal König, Kim Meichtry-Stier, Ester Pellegrini, Deborah Ramseier, and Silvan Rüttimann, for their help with the fieldwork. Jérôme Guélat helped kindly with the home-range size estimation and the GIS analyses. We thank Susanne Jenni-Eiermann, KimWallen, and the associate editor for the helpful comments on an earlier version of the manuscript. The Swiss National Science Foundation supported financially the study (no. 3100A0-104134 to LJ and SJE, no. PP00A0102913 and 3100AO_120517 to AR).

\section{References}

Almasi, B., Roulin, A., Jenni-Eiermann, S., Jenni, L., 2008. Parental investment and its sensitivity to corticosterone is linked to melanin-based coloration in barn owls. Horm. Behav. 54, 217-223.

Almasi, B., Jenni, L., Jenni-Eiermann, S., Roulin, A., 2010. Regulation of stress response is heritable and functionally linked to melanin-based coloration. J. Evol. Biol. 23, 987-996.

Almasi, B., Rettenbacher, S., Müller, C., Wagner, H., Brill, S., Jenni, L., 2012. Materna corticosterone is transferred into the egg yolk. Gen. Comp. Endocrinol. 178, 139-144.

Almasi, B., Roulin, A., Korner-Nievergelt, F., Jenni-Eiermann, S., Jenni, L., 2012. Coloration signals the ability to cope with elevated stress hormones: effects of corticosterone on growth of barn owls are associated with melanism. J. Evol. Biol. 25, 1189-1199.

Alonso-Alvarez, C., Bertrand, S., Devevey, G., Prost, J., Faivre, B., Sorci, G., 2004. Increased susceptibility to oxidative stress as a proximate cost of reproduction. Ecol. Lett. 7, 363-368.

Bundesamt für Statistik, 2001. Arealstatistik Schweiz: Bodennutzung im Wandel 3-303-02061-2.

Calenge, C., 2006. The package "adehabitat" for the R software: a tool for the analysis of space and habitat use by animals. Ecol. Model. 197, 516-519.

Chaine, A.S., Tjernell, K.A., Shizuka, D., Lyon, B.E., 2011. Sparrows use multiple status signals in winter social flocks. Anim. Behav, 81, 447-453.

DeNardo, D.F., Sinervo, B., 1994. Effects of Corticosterone on Activity and Home-Range Size of Free-Ranging Male Lizards. Horm. Behav. 28, 53-65.

R Development Core Team, 2010. R: A language and environment for statistica computing. R Development Core Team. Vienna, Austria, R Foundation for Statistical Computing. Ref Type: Computer Program.

Dreiss, A.N., Henry, I., Ruppli, C.A., Almasi, B., Roulin, A., 2010. Darker eumelanic barn owls better withstand food depletion through resistance to food deprivation and lower appetite. Oecologia 164, 65-71.

Ducrest, A.-L., Keller, L., Roulin, A., 2008. Pleiotropy in the melanocortin system, coloration and behavioural syndromes. Trends Ecol. Evol. 23, 502-510.

Durant, J.M., Gendner, J.-P., Handrich, Y., 2004. Should I brood or should I hunt: a female barn owl's dilemma. Can. J. Zool. 82, 1011-1016.

Jacquin, L., Récapet, C., Bouche, P., Leboucher, G., Gasparini, J., 2012. Melanin-based coloration reflects alternative strategies to cope with food limitation in pigeons. Behav. Ecol. 23, 907-915.

Kenward, R.E., 2001. A Manual for Wildlife Radio Tagging. Academic Press, San Diego.

Kingma, S.A., Szentirmai, I., Szekely, T., Bokony, V., Bleeker, M., Liker, A., Komdeur, J. 2008. Sexual selection and the function of a melanin-based plumage ornament in polygamous penduline tits Remiz pendulinus. Behav. Ecol. Sociobiol. 62, 1277-1288.

Kittilsen, S., Schjolden, J., Beitnes-Johansen, I., Shaw, J.C., Pottinger, T.G., Sorensen, C, Braastad, B.O., Bakken, M., Overli, O., 2009. Melanin-based skin spots reflect stress responsiveness in salmonid fish. Horm. Behav. 56, 292-298.

Kittilsen, S., Beitnes-Johansen, I., Braastad, B.O., Overli, O., 2012. Pigments, parasites and personality: towards a unifying role for steroid hormones? PLoS One 7, e34281.
Müller, C., Jenni-Eiermann, S., Blondel, J., Perret, P., Caro, S.P., Lambrechts, M., Jenni, L., 2006. Effect of human presence and handling on circulating corticosterone levels in breeding blue tits (Parus caeruleus). Gen. Comp. Endocrinol. 148, 163-171.

Müller, C., Almasi, B., Roulin, A., Breuner, C.W., Jenni-Eiermann, S., Jenni, L., 2009. Effects of corticosterone pellets on baseline and stress-induced corticosterone and corticosteroid-binding-globulin. Gen. Comp. Endocrinal. 160, 59-66.

Munro, C.J., Lasley, B.L., 1988. Non-radiometric methods for immunoassay of steroid hormones. In: Albertson, B.D., Haseltine, F.P. (Eds.), Non-radiometric Assays: Technology and Application in Polypeptide and Steroid Hormone Detection. Alan R. Liss Inc., New York, pp. 289-329.

Munro, C.J., Stabenfeldt, G., 1984. Development of a microtitre plate enzyme immunoassay for the determination of progesterone. J. Endocrinol. 101, 41-49.

Naef-Daenzer, B., 2007. An allometric function to fit leg-loop harnesses to terrestrial birds. J. Avian Biol. 38, 404-407.

Piault, R., Gasparini, J., Bize, P., Jenni-Eiermann, S., Roulin, A., 2009. Pheomelanin-based coloration and the ability to cope with variation in food supply and parasitism. Am. Nat. 174, 548-556

Pryke, S.R., Astheimer, L.B., Griffith, S.C., Buttemer, W.A., 2012. Covariation in lifehistory traits: differential effects of diet on condition, hormones, behavior, and reproduction in genetic finch morphs. Am. Nat. 179, 375-390.

Roulin, A., 1999. Nonrandom pairing by male barn owls (Tyto alba) with respect to a female plumage trait. Behav. Ecol. 10, 688-695.

Roulin, A., 2001. Food supply differentially affects sibling negotiation and competition in the barn owl (Tyto alba). Behav. Ecol. Sociobiol. 49, 344-348.

Roulin, A., 2004. Proximate basis of the covariation between a melanin-based female ornament and offspring quality. Oecologia 140, 668-675.

Roulin, A., 2009. Covariation between eumelanic pigmentation and body mass only under specific conditions. Naturwissenschaften 96, 375-382.

Roulin, A., Altwegg, R., 2007. Breeding rate is associated with pheomelanism in male and with eumelanism in female barn owls. Behav. Ecol. 18, 563-570.

Roulin, A., Dijkstra, C., 2003. Genetic and environmental components of variation in eumelanin and phaeomelanin sex-traits in the barn owl. Heredity 90, 359-364.

Roulin, A., Dijkstra, C., Riols, C., Ducrest, A.L., 2001. Female- and male-specific signals of quality in the barn owl. J. Evol. Biol. 14, 255-266.

Roulin, A., Dauwe, T., Blust, R., Eens, M., Beaud, M., 2006. A link between eumelanism and calcium physiology in the barn owl. Naturwissenschaften 93, 426-430.

Roulin, A., Almasi, B., Rossi-Pedruzzi, A., Ducrest, A.L., Wakamatsu, K., Miksik, I., Blount, J.D., Jenni-Eiermann, S., Jenni, L., 2008. Corticosterone mediates the condition-dependent component of melanin-based coloration. Anim. Behav. 75, 1351-1358.

Roulin, A., Altwegg, R., Jensen, H., Steinsland, I., Schaub, M., 2010. Sex-dependent selection on an autosomal melanic female ornament promotes the evolution of sex ratio bias. Ecol. Lett. 13, 616-626.

Roulin, A., Almasi, B., Meichtry-Stier, K.S., Jenni, L., 2011. Eumelanin- and pheomelaninbased colour advertise resistance to oxidative stress in opposite ways. J. Evol. Biol. 24, 2241-2247.

Roulin, A., Antoniazza, S., Burri, R., 2011. Spatial variation in the temporal change of male and female melanic ornamentation in the barn owl. J. Evol. Biol. 24, 1403-1409.

Sapolsky, R.M., Romero, L.M., Munck, A.U., 2000. How do glucocorticoids influence stress responses? Integrating permissive, suppressive, stimulatory, and preparative actions. Endocr. Rev. 21, 55-89.

Schwabl, H., 1995. Individual variation of the acute adrenocortical response to stress in the white-throated sparrow. Zoology Anal. Complex Syst. 99, 113-120.

Senar, J.C., Polo, V., Uribe, F., Camerino, M., 2000. Status signalling, metabolic rate and body mass in the siskin: the cost of being a subordinate. Anim. Behav. 59, 103-110.

Stearns, S.C., 1992. The Evolution of Life Histories. Oxford University Press, Oxford.

Taylor, I.R., 1993. Age and sex determination of barn owls Tyto alba alba. Ringing Migr. 14, 94-102.

Worton, B.J., 1989. Kernel methods for estimating the utilization distribution in homerange studies. Ecology 70, 164-168. 